\title{
Efficacy and Safety of Picosecond-Domain Neodymium-Doped Yttrium Aluminum Garnet Laser Treatment on Various Causes of Traumatic Tattoos
}

\author{
Boncheol Leo Goo' \\ Sung Bin $\mathrm{Cho}^{2,3}$
}

${ }^{1}$ Naeum Dermatology and Aesthetic Clinic, Seoul,
Korea
${ }^{2}$ Department of Dermatology, International St.
Mary's Hospital, Catholic Kwandong University
College of Medicine, Incheon, Korea
${ }^{3}$ Kangskin Sillim Dermatology Clinic, Seoul,
Korea

Received August 30, 2016

Accepted September 9, 2016

Correspondence
Sung Bin Cho
Department of Dermatology, International
St. Mary's Hospital, Catholic Kwandong University
College of Medicine, 25 Simgok-ro, Seo-gu,
Incheon 22711, Korea
Tel.: +82-32-290-3141
Fax: +82-32-290-3142
E-mail: drsbcholdgmail.com
(C) Korean Society for Laser Medicine and Surgery
@ This is an open access article distributed under the
terms of the Creative Commons Attribution Non-
Commercial License (http://creativecommons.org/
licenses/by-nc/4.0) which permits unrestricted non-
commercial use, distribution, and reproduction in any
medium, provided the original work is properly cited.

\begin{abstract}
Background and Objectives
Occurring accidentally, traumatic tattoos result from the forceful embedding of foreign bodies, such as graphite, asphalt, petroleum products, sand, metals, glass, gunpowder, or dust, into the skin. Laser therapy is the first-line treatment for the removal of traumatic tattoos. The aim of this case series was to analyze the clinical efficacy and safety of treating traumatic tattoos of various causes with a picosecond-domain, 1,064-nm neodymium-doped yttrium aluminum garnet (Nd:YAG) laser.
\end{abstract}

\section{Materials and Methods \\ Upon treatment with the laser, objective clinical improvement in the appearances of the traumatic tattoos was analyzed in nine Korean patients (five men and four women with a mean age of $28.3 \pm 11.1$ years). Among the subjects, the causes of the traumatic tattoos included abrasion wounds from falls $(N=6)$, wounds from motor-vehicle accidents $(N=2)$, and a pencil point puncture $(N=1)$.}

\section{Results}

Overall, the mean objective improvement score at one month after the final treatment was $2.4 \pm 0.7$. Five of the nine $(55.6 \%)$ patients showed clinical improvement of grade 3. Three (33.3\%) patients demonstrated clinical improvement of grade 2. One (11.1\%) experienced grade 1 improvement. In addition, traumatic tattoo-associated textural impairments also generally improved after the picosecond-domain, 1,064-nm Nd:YAG laser treatment without the need for additional scar treatments.

\section{Conclusion}

The treatment of traumatic tattoos of varying causes in Korean patients with a 1,064-nm, picosecond-domain Nd:YAG laser is effective and safe. Nevertheless, further split-design investigations to compare the therapeutic effects between nanosecond- and picosecond-domain $\mathrm{Nd}$ :YAG lasers will be needed to confirm these findings.

\section{Key words}

Laser; Neodymium-doped yttrium aluminum garnet; Pulse duration; Picosecond; Tattoo pigment 


\section{INTRODUCTION}

Applied as body art or as a therapeutic modality, tattoos are categorized into cosmetic, professional, amateur, and medical tattoos. ${ }^{1-3}$ Meanwhile, however, pigmented wounds arising from various sources of trauma are also categorized as tattoos, traumatic ones. ${ }^{2}$ These tattoos involve the forceful embedding of foreign bodies into the skin: potential materials include graphite, asphalt, petroleum products, sand, metals, glass, gunpowder, or dust. ${ }^{4}$ When pigmented foreign bodies enter into the dermis, large phagosomes found in keratinocytes, macrophages, and mesenchymal cells engulf the particles, creating varying degrees of hypertrophic scar tissue., ${ }^{5,6}$

Laser therapy has been regarded as the first-line treatment of choice for the removal of all types of tattoo pigments. ${ }^{1,2}$ Furthermore, although traumatic tattoos clinically present as pigmented lesions with scarring and textural alterations, nanosecond-domain lasers, including ruby, alexandrite, and neodymium-doped yttrium aluminum garnet (Nd:YAG) lasers, have been found to be clinically effective in treating traumatic tattoos. ${ }^{1,2,4,7,8}$ By delivering nanosecond-domain laser energy to the tattoo substances, explosive expansion of chromophores in the tattoo pigment results in fragmentation thereof into smaller particles by selective photothermolysis. ${ }^{1,2}$ Rapid heating of target chromophores via selective photothermolysis usually occurs after treatment with nanoseconddomain lasers; however, oftentimes, the temperature does not reach the melting threshold of tattoo pigments.? Moreover, one study has reported that the photoacoustic effects induced by a laser are more essential to tattoo removal than its photothermal effects, as laser-induced photothermal reactions mainly influence the surrounding tissue.?

Laser-assisted tattoo removal using a shorter pulse duration has been shown to be more effective breaking down tattoo particles than those with a long pulse duration. ${ }^{9}$ Furthermore, successive in vivo and in vitro experiments have found picosecond-domain lasers to be more advantageous in breaking down tattoo pigments of various colors and constituents than nanosecond-domain lasers. ${ }^{10-15}$ In the present case series study, we analyzed the clinical efficacy and safety of a picosecond-domain $\mathrm{Nd}$ :YAG laser in the treatment of traumatic tattoos of various causes.

\section{PATIENTS AND METHODS}

Nine Korean patients (five men and four women with a mean age of $28.3 \pm 11.1$ years, ranging from 12 to 47 years) with Fitzpatrick skin type III-IV were scheduled to undergo treatment with a picosecond-domain, 1,064-nm Nd:YAG laser (PICOPLUS; Lutronic Corp., Goyang, Korea) to treat traumatic tattoos. Table 1 summarizes their demographics. Among the subjects of this study, the causes of traumatic tattoos included abrasion wounds from a fall $(N=6)$, wounds from motor-vehicle accidents $(N=2)$, and a pencil point puncture wound $(N=1)$. The patients reported no past history of treatment for their tattoos, including surgical excision; topical bleaching agents containing hydroquinone, retinoic acid, and/or $\alpha$-hydroxy acid; chemical peels; dermabrasion; and laser or light therapies. Moreover, none of the patients involved a high probability of becoming pregnant or a propensity for keloids or immunosuppression.

Table 1. Baseline patient characteristics and clinical outcomes following treatment with a picosecond-domain 1,064-nm neodymium-doped yttrium aluminum garnet (Nd:YAG) laser

\begin{tabular}{|c|c|c|c|c|c|c|c|}
\hline \multirow[b]{2}{*}{ Pt. No. } & \multirow{2}{*}{$\begin{array}{c}\text { Sex/age } \\
\text { (years) }\end{array}$} & \multirow[b]{2}{*}{ Cause } & \multirow{2}{*}{$\begin{array}{l}\text { Site/duration } \\
\text { (months) }\end{array}$} & \multirow{2}{*}{$\begin{array}{c}\text { Spot size }(\mathrm{mm}) / \\
\text { laser fluence }\left(\mathrm{J} / \mathrm{cm}^{2}\right)\end{array}$} & \multirow{2}{*}{$\begin{array}{l}\text { No. of picosecond laser } \\
\text { treatments/interval } \\
\text { (weeks) }\end{array}$} & \multicolumn{2}{|c|}{ Global improvement } \\
\hline & & & & & & $\begin{array}{l}\text { Objective clinical } \\
\text { improvement }\end{array}$ & $\begin{array}{l}\text { Patient degree of } \\
\text { satisfaction }\end{array}$ \\
\hline 1 & $M / 21$ & Fall abrasion & Forehead/24 & 4/1.6-2.2. & $3 / 4$ & 3 & 2 \\
\hline 2 & $M / 22$ & Fall abrasion & Zygoma/6 & $3 / 1.2-3.4$ & $2 / 4$ & 3 & 3 \\
\hline 3 & $\mathrm{~F} / 30$ & Fall abrasion & Zygoma/3 & $6 / 0.6$ & $3 / 2$ & 2 & 3 \\
\hline 4 & $\mathrm{~F} / 42$ & Motor-vehicle accident & Zygoma/60 & $6 / 0.6$ & $3 / 2$ & 2 & 2 \\
\hline 5 & $\mathrm{~F} / 47$ & Fall abrasion & Chin and cheek/18 & $6 / 0.6$ & $3 / 2$ & 3 & 2 \\
\hline 6 & $\mathrm{M} / 23$ & Fall abrasion & Zygoma/18 & $4 / 2.4$ & $1 / 4$ & 3 & 3 \\
\hline 7 & $F / 24$ & Pencil point puncture & Nose/144 & $4 / 2.8$ & $2 / 4$ & 2 & 3 \\
\hline 8 & $\mathrm{M} / 34$ & Motor-vehicle accident & Eyelid/72 & $4 / 2.6$ & $1 / \mathrm{NA}$ & 1 & 2 \\
\hline 9 & $\mathrm{M} / 12$ & Fall abrasion & Chin and cheek/18 & $4 / 1.8$ & $3 / 2$ & 3 & 3 \\
\hline
\end{tabular}

NA, not applicable. 
After obtaining written informed consent, all enrolled subjects were treated with one to three sessions of treatment with a picosecond-domain, 1,064-nm Nd:YAG laser. At each laser treatment session, a single or two passes were made with the device after administering local anesthesia with topical EMLA cream leutectic mixture of $2.5 \%$ lidocaine $\mathrm{HCl}$ and $2.5 \%$ prilocaine; AstraZeneca $A B$, Södertälje, Sweden). The laser settings comprised a $1,064-\mathrm{nm}$ wavelength and a pulse energy of $1.2-3.4 \mathrm{~J} / \mathrm{cm}^{2}$ at a 3-mm spot size, a pulse energy of $1.6-2.8 \mathrm{~J} / \mathrm{cm}^{2}$ at a 4-mm spot size, or a pulse energy of $0.6 \mathrm{~J} / \mathrm{cm}^{2}$ at a $6-\mathrm{mm}$ spot size. Treatment sessions were scheduled at 2-4week intervals. Immediately after treatment, the treated area was cooled with icepacks. During the course of the laser treatments, patients were recommended to apply a broad-spectrum sunscreen and avoid excessive sun exposure.

At baseline and one month after the final treatment, digital photographs were taken with the patients placed in an identical position and under the same light settings. Thereafter, two dermatologists evaluated objective clinical improvement in the tattoo lesions by analyzing photographs according to the global aesthetic improvement scale (GAIS), scoring them as "worse than before" (score:
-1), "clinically unchanged" (score: 0), "slightly improved" (score: 1), "moderately improved" (score: 2), or "markedly improved" (score: 3). Additionally, patients were asked to subjectively report their satisfaction with the treatment course as "unsatisfied" (score: 0), "slightly satisfied" (score: 1), "satisfied" (score: 2), or "very satisfied" (score: 3), as well as any side effects, including bleeding, oozing, post-therapy dyschromias, scaling, crusting, prolonged erythema, and scarring.

\section{RESULTS}

One month after the final treatment, the overall mean objective improvement score was $2.4 \pm 0.7$. Five of the nine (55.6\%) patients presented clinical improvement of grade 3 (Fig. 1, 2), three (33.3\%) patients exhibited clinical improvement of grade 2 (Fig. 3, 4), and one (11.1\%) showed grade 1 improvement. The patients' overall mean subjective satisfaction with the treatment results was 2.6 \pm 0.5 . Five of the nine (55.6\%) patients reported subjective satisfaction of grade 3 and the four (44.4\%) remaining patients achieved subjective satisfaction of grade 2 .

Among the nine patients with traumatic tattoos, those with tattoos from a fall achieved higher objective improve-
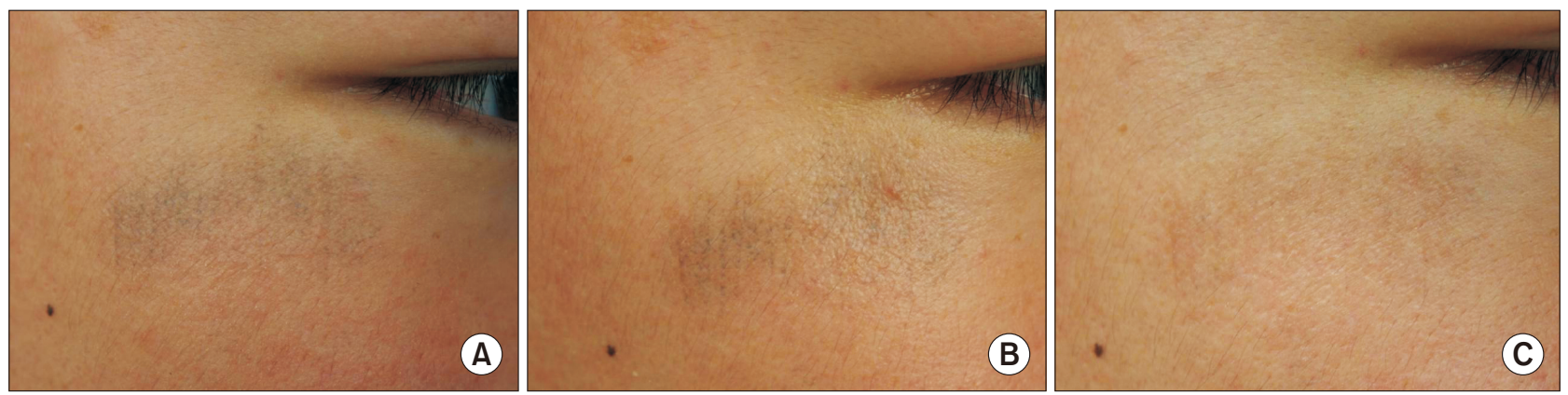

Fig. 1. Traumatic tattoo from a fall on the zygoma in Patient 2. (A) Baseline, (B) one month after the first session, and (C) one month after the second session of picosecond-domain 1,064-nm neodymium-doped yttrium aluminum garnet (Nd:YAG) laser treatment.
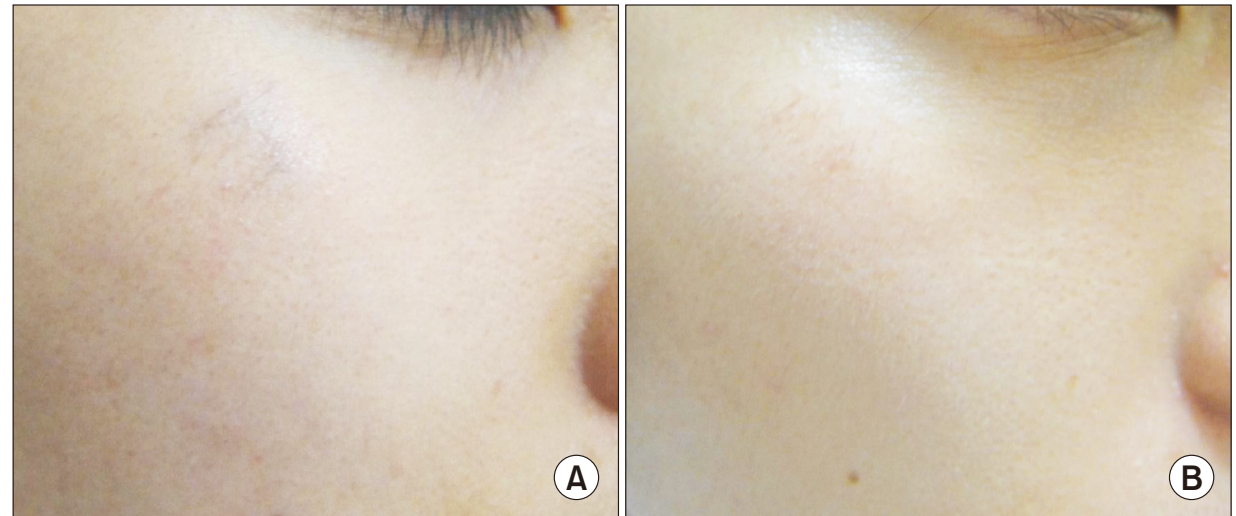

Fig. 2. Traumatic tattoo from a fall on the zygoma in Patient 6. (A) Baseline and (B) one month after one session of picosecond-domain 1,064-nm Nd:YAG laser treatment. 

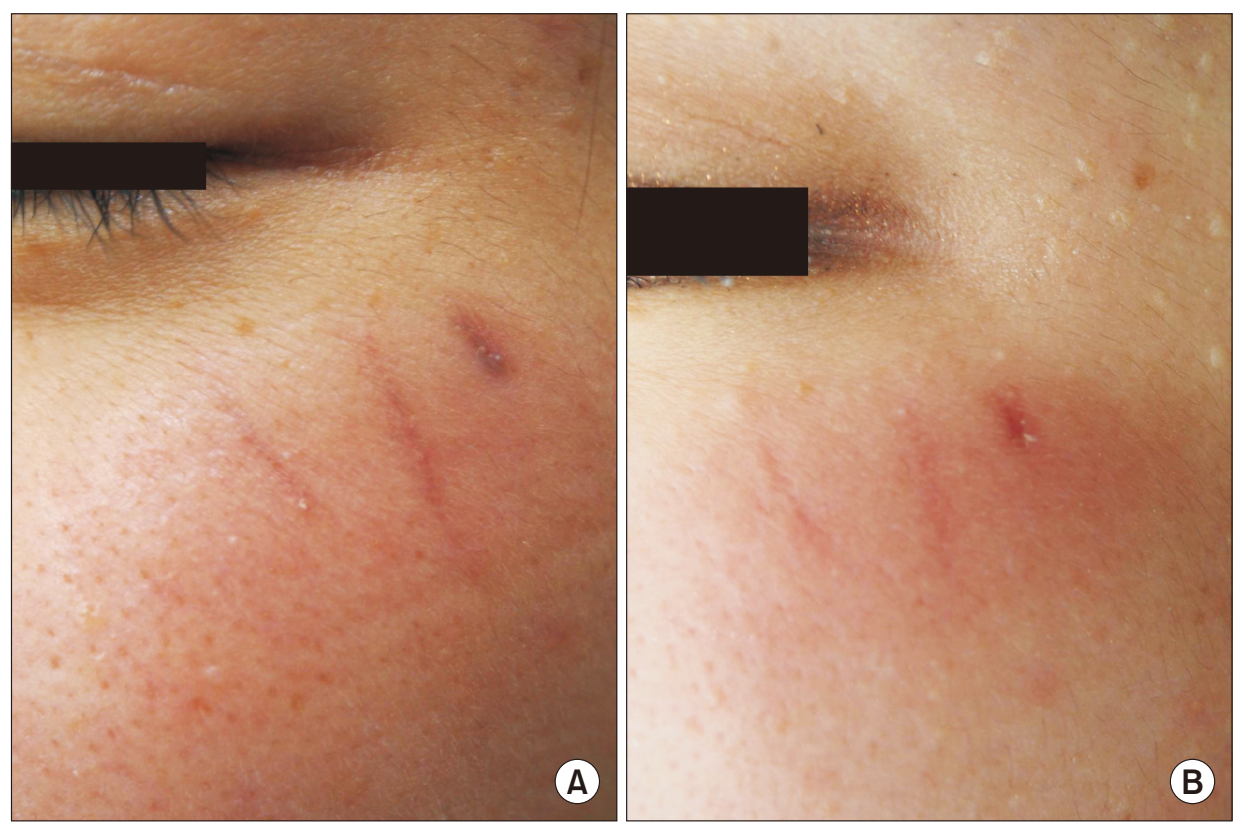

Fig. 3. Traumatic tattoo from a fall on the zygoma in Patient 3. (A) Baseline and (B) one month after three sessions of picosecond-domain 1,064-nm Nd:YAG laser treatment.

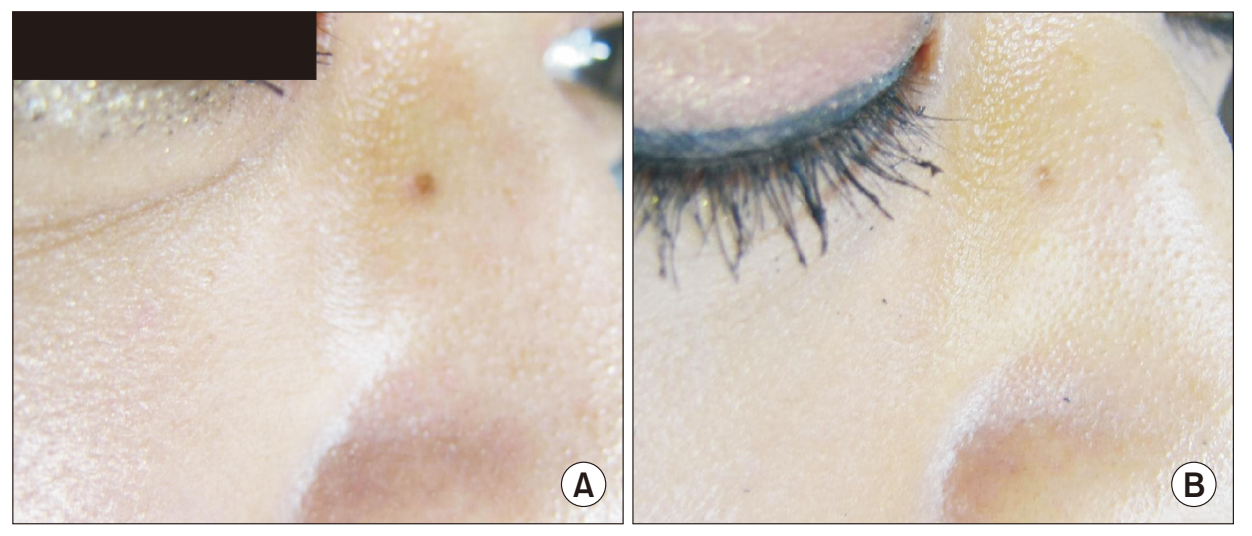

Fig. 4. Pencil point puncture-induced traumatic tattoo on the nose in patient 7. (A) Baseline and (B) one month after two sessions of picoseconddomain 1,064-nm Nd:YAG laser treatment.

ment and satisfaction with the treatment than the others, regardless of age, sex, and duration and location of their traumatic tattoo. Meanwhile, individuals with tattoos stemming from motor-vehicle accidents also presented good therapeutic outcomes, but relatively lower satisfaction with the treatment, compared to those with tattoos from a fall. In all patients, textural impairments associated with the traumatic tattoos, including atrophic and hypertrophic scars, generally improved after the laser treatment without the need for additional scar treatments.

A frosted appearance of the laser treated area was mild and manageable only by cooling with icepacks. Additionally, patient surveys revealed that any pain during and immediately after the laser treatment was tolerable with only application of topical anesthetic cream. Immediately after the treatment, petechial appearance of the treated areas was noticeable. However, post-therapy blister for- mation, bleeding, and oozing were not observed. Other possible adverse events, including post-therapy dyschromias, and secondary bacterial, viral, fungal, or mycobacterium infection, and scarring, were not encountered.

\section{DISCUSSION}

Traumatic tattoo formation is preventable with immediate and complete removal of forcefully embedded foreign materials into the skin prior to recovery of epidermal and dermal tissues. ${ }^{4}$ Failure to do so can leave a mark on the skin that likely necessitates laser-assisted treatment for removal. Previous investigations using nanoseconddomain lasers demonstrated that 1.7 to 2.4 sessions of Q-switched alexandrite laser treatment, 1.7 sessions of Q-switched Nd:YAG laser treatment, or even a single session of Q-switched Nd:YAG laser treatment results in 
moderate to marked clinical improvement in traumatic tattoo lesions. ${ }^{4.16-18}$ Furthermore, in cases with large embedded traumatic tattoos, the use of ablative lasers, particularly an erbium:YAG laser, alone or in combination with pigment lasers provides satisfactory clinical outcomes. ${ }^{19,20}$ However, in Asian patients, risk of posttreatment hyper- or hypopigmentation, textural alteration, and scarring is a concern. ${ }^{1,2,4}$

Picosecond-domain laser devices irradiate laser energy at extremely shorter pulse durations than nanoseconddomain lasers. Thereby, picosecond laser pulses are able to generate photothermal reactions more rapidly and deliver photoacoustic effects more extensively to target chromophores and surrounding tissues. ${ }^{2,10-15}$ Several clinical and experimental reports have revealed that various colors of tattoo chromophores can be effectively treated by picosecond lasers with a greater treatment response over fewer treatment sessions. ${ }^{10-15}$ In the present study, we also found that asphalt- and sand-embedded tattoos caused by abrasions from a fall or motor-vehicle accident and a graphite-embedded, pencil point puncture tattoo were effectively and safely cleared after 1-3 sessions of 1,064-nm, picosecond-domain Nd:YAG laser treatment. We suggest that the explosive but selective delivery of photoacoustic waves could have contributed to the rapid clinical improvement in the traumatic tattoos from various foreign bodies.

We treated the patients with traumatic tattoos in this study with a pulse energy of $1.2-3.4 \mathrm{~J} / \mathrm{cm}^{2}$ at a $3-\mathrm{mm}$ spot size, a pulse energy of $1.6-2.8 \mathrm{~J} / \mathrm{cm}^{2}$ at a $4-\mathrm{mm}$ spot size, or a pulse energy of $0.6 \mathrm{~J} / \mathrm{cm}^{2}$ at a $6-\mathrm{mm}$ spot size at 2-4-week intervals. Compared to previous nanoseconddomain laser treatment for traumatic tattoo removal, which recommended a pulse energy of $7.0-8.0 \mathrm{~J} / \mathrm{cm}^{2,4,18}$ approximately $50 \%$ less laser fluence was used in this study, and the therapeutic outcomes seemed to be comparably similar or better. Moreover, when using a pulse energy of $0.6 \mathrm{~J} / \mathrm{cm}^{2}$ at a $6-\mathrm{mm}$ spot size, the picosecondlaser treatments were able to be safely performed even at 2-week intervals. Notwithstanding, the optimum treatment settings of picosecond lasers in the treatment of traumatic tattoos, which involve various substances other than merely ink, remains to be investigated.

While the most important mechanism contributing to tattoo clearance via laser treatment is its photoacoustic effects, ${ }^{4,9}$ photothermal effects stimulate remarkable localization of heat-induced vacuolization to the surrounding tissues, which clinically appears as a frosted appearance of the irradiated lesions. In this case series, we experienced that the pain during and after the pico- second laser treatment was better tolerable and that the immediate frosted appearance of irradiated lesions was less remarkable in picosecond laser treatment than what we are accustomed to in nanosecond laser. Therefore, the post-treatment frosted appearance after picosecond laser treatment seemed to be less reliable for determining therapeutic end-points.

In the present case series, we demonstrated the clinical efficacy and safety of 1,064-nm, picosecond-domain $\mathrm{Nd}$ :YAG laser in the treatment of various traumatic tattoos in Korean patients. However, comparative evaluation between nanosecond-domain and picosecond-domain lasers could not be performed in this study due to the heterogeneity of the traumatic tattoos in causes, sites, and components. Moving forward, further split-design investigations to compare the therapeutic effects between nanosecond- and picosecond-domain Nd:YAG lasers are needed to confirm our findings.

\section{ACKNOWLEDGMENTS}

We would like to thank Anthony Thomas Milliken, ELS, (Editing Synthase, Seoul, Korea) for his help with the editing of this manuscript.

\section{REFERENCES}

1. Choudhary S, Elsaie ML, Leiva A, Nouri K. Lasers for tattoo removal: a review. Lasers Med Sci 2010;25:619-27.

2. Kent KM, Graber EM. Laser tattoo removal: a review. Dermatol Surg 2012;38:1-13.

3. Pfirrmann G, Karsai S, Roos S, Hammes S, Raulin C. Tattoo removal--state of the art. J Dtsch Dermatol Ges 2007;5:889-97.

4. Gorouhi F, Davari P, Kashani MN, Firooz A. Treatment of traumatic tattoo with the Q-switched Nd:YAG laser. J Cosmet Laser Ther 2007;9:253-5.

5. Barua S. Laser-tissue interaction in tattoo removal by q-switched lasers. J Cutan Aesthet Surg 2015;8:5-8.

6. Beute TC, Miller $\mathrm{CH}$, Timko AL, Ross EV. In vitro spectral analysis of tattoo pigments. Dermatol Surg 2008;34:508-15.

7. Achauer BM, Nelson JS, Vander Kam VM, Applebaum R. Treatment of traumatic tattoos by $\mathrm{Q}$-switched ruby laser. Plast Reconstr Surg 1994:93:318-23.

8. Ashinoff R, Geronemus RG. Rapid response of traumatic and medical tattoos to treatment with the $\mathrm{Q}$-switched ruby laser. Plast Reconstr Surg 1993;91:841-5.

9. Ho DD, London R, Zimmerman GB, Young DA. Laser-tattoo removal--a study of the mechanism and the optimal treatment strategy via computer simulations. Lasers Surg Med 2002;30: 389-97. 
10. Ross V, Naseef G, Lin G, Kelly M, Michaud N, Flotte TJ, et al. Comparison of responses of tattoos to picosecond and nanosecond Q-switched neodymium: YAG lasers. Arch Dermatol 1998;134:167-71.

11. Herd RM, Alora MB, Smoller B, Arndt KA, Dover JS. A clinical and histologic prospective controlled comparative study of the picosecond titanium:sapphire $(795 \mathrm{~nm}$ ) laser versus the Q-switched alexandrite (752 nm) laser for removing tattoo pigment. J Am Acad Dermatol 1999;40:603-6.

12. Ibrahimi OA, Sakamoto FH, Anderson RR. Picosecond laser pulses for tattoo removal: a good, old idea. JAMA Dermatol 2013;149:241.

13. Izikson L, Farinelli W, Sakamoto F, Tannous Z, Anderson RR. Safety and effectiveness of black tattoo clearance in a pig model after a single treatment with a novel $758 \mathrm{~nm} 500$ picosecond laser: a pilot study. Lasers Surg Med 2010;42:6406.

14. Brauer JA, Reddy KK, Anolik R, Weiss ET, Karen JK, Hale EK, et al. Successful and rapid treatment of blue and green tattoo pigment with a novel picosecond laser. Arch Dermatol
2012;148:820-3.

15. Saedi N, Metelitsa A, Petrell K, Arndt KA, Dover JS. Treatment of tattoos with a picosecond alexandrite laser: a prospective trial. Arch Dermatol 2012;148:1360-3.

16. Suzuki H. Treatment of traumatic tattoos with the Q-switched neodymium:YAG laser. Arch Dermatol 1996;132:1226-9.

17. Moreno-Arias GA, Casals-Andreu M, Camps-Fresneda A. Use of Q-switched alexandrite laser (755 nm, $100 \mathrm{nsec)}$ for removal of traumatic tattoo of different origins. Lasers Surg Med 1999; 25:445-50

18. Chang SE, Choi JH, Moon KC, Koh JK, Sung KJ. Successful removal of traumatic tattoos in Asian skin with a $Q$-switched alexandrite laser. Dermatol Surg 1998;24:1308-11.

19. Kunzi-Rapp K, Krähn GM, Wortmann S, Peter RU. Early treatment of traumatic tattoo by erbium-YAG laser. Br J Dermatol 2001;144:219-21.

20. Cambier B, Rogge F. Traumatic tattoo: use of the variable pulsed erbium:YAG laser. Photomed Laser Surg 2006:24:6059. 